\title{
Evaluation of the ETS-Lindgren Open Boundary Quad-Ridged Horn 3164-06
}

\author{
by Christopher S Kenyon
}

ARL-TR-7272

April 2015 


\section{NOTICES}

\section{Disclaimers}

The findings in this report are not to be construed as an official Department of the Army position unless so designated by other authorized documents.

Citation of manufacturer's or trade names does not constitute an official endorsement or approval of the use thereof.

Destroy this report when it is no longer needed. Do not return it to the originator. 


\title{
Army Research Laboratory
}

Adelphi, MD 20783-1138

ARL-TR-7272

April 2015

\section{Evaluation of the ETS-Lindgren Open Boundary Quad-Ridged Horn 3164-06}

\author{
Christopher S Kenyon \\ Sensors and Electron Devices Directorate, ARL
}


Public reporting burden for this collection of information is estimated to average 1 hour per response, including the time for reviewing instructions, searching existing data sources, gathering and maintaining the data needed, and completing and reviewing the collection information Send comments regarding this burden estimate or any other aspect of this collection of information, including suggestions for reducing the burden, to Department of Defense, Washington Headquarters Services, Directorate for Information Operations and Reports (0704-0188), 1215 Jefferson Davis Highway, Suite 1204, Arlington, VA 22202-4302 Respondents should be aware that notwithstanding any other provision of law, no person shall be subject to any penalty for failing to comply with a collection of information if it does not display a currently valid OMB control number

PLEASE DO NOT RETURN YOUR FORM TO THE ABOVE ADDRESS.

\begin{tabular}{|c|c|c|}
\hline $\begin{array}{l}\text { 1. REPORT DATE (DD-MM- } Y Y Y Y) \\
\text { April } 2015\end{array}$ & $\begin{array}{l}\text { 2. REPORT TYPE } \\
\text { Final }\end{array}$ & $\begin{array}{l}\text { 3. DATES COVERED (From - To) } \\
10 / 2012-7 / 2014\end{array}$ \\
\hline \multirow{4}{*}{\multicolumn{2}{|c|}{$\begin{array}{l}\text { 4. TITLE AND SUBTITLE } \\
\text { Evaluation of the ETS-Lindgren Open Boundary Quad-Ridged Horn 3164-06 }\end{array}$}} & 5a. CONTRACT NUMBER \\
\hline & & \\
\hline & & 5b. GRANT NUMBER \\
\hline & & 5c. PROGRAM ELEMENT NUMBER \\
\hline \multirow{3}{*}{\multicolumn{2}{|c|}{$\begin{array}{l}\text { 6. AUTHOR(S) } \\
\text { Christopher S Kenyon }\end{array}$}} & 5d. PROJECT NUMBER \\
\hline & & 5e. TASK NUMBER \\
\hline & & 5f. WORK UNIT NUMBER \\
\hline \multicolumn{2}{|c|}{$\begin{array}{l}\text { 7. PERFORMING ORGANIZATION NAME(S) AND ADDRESS(ES) } \\
\text { US Army Research Laboratory } \\
\text { ATTN: RDRL-SER-U } \\
\text { 2800 Powder Mill Road } \\
\text { Adelphi, MD 20783-1138 }\end{array}$} & $\begin{array}{l}\text { 8. PERFORMING ORGANIZATION } \\
\text { REPORT NUMBER } \\
\text { ARL-TR-7272 }\end{array}$ \\
\hline \multirow{2}{*}{\multicolumn{2}{|c|}{ 9. SPONSORING/MONITORING AGENCY NAME(S) AND ADDRESS(ES) }} & 10. SPONSOR/MONITOR'S ACRONYM(S) \\
\hline & & $\begin{array}{l}\text { 11. SPONSOR/MONITOR'S REPORT } \\
\text { NUMBER(S) }\end{array}$ \\
\hline
\end{tabular}

\section{DISTRIBUTIONIAVAILABILITY STATEMENT}

Approved for public release; distribution unlimited.

\section{SUPPLEMENTARY NOTES}

\section{ABSTRACT}

The ETS-Lindgren quad-ridged, open boundary horn, model 3164-06, was modeled using FEKO computational software. Its gains were measured in the US Army Research Laboratory (ARL) building 504 anechoic chamber and its patterns and S11 parameters were measured in building 203 tapered chamber to characterize its electrical properties. These models and measurements were compared with each other and with the characterization given by its manufacturer, ETS-Lindgren. Results from simplified FEKO computer models of the antenna and measurements performed at ARL largely agreed with the ETSLindgren characterization given by a "typical" 3164-06 antenna in its manual. Strong oscillations in the frequency spectrum for the S11 (and therefore the voltage standing wave ratio [VSWR]) in the ARL measurements may be an exception, though more such measurements are needed.

\section{SUBJECT TERMS}

ETS-Lindgren, Quad-ridged, horn, S11, gain pattern, FEKO, model

\section{SECURITY CLASSIFICATION OF:}

A. Report

Unclassified

b. ABSTRACT

Unclassified

\section{c. THIS PAGE}

Unclassified

\begin{tabular}{l|c}
\begin{tabular}{l|} 
17. LIMITATION \\
OF
\end{tabular} & $\begin{array}{c}\text { 18. NUMBER } \\
\text { OF } \\
\text { ABSTRACT }\end{array}$ \\
PAGES \\
UU & 22
\end{tabular}

19a. NAME OF RESPONSIBLE PERSON

Christopher S Kenyon

19b. TELEPHONE NUMBER (Include area code) 301-394-5547 


\section{Contents}

List of Figures $\quad$ iv

$\begin{array}{ll}\text { Acknowledgments } & \text { v }\end{array}$

$\begin{array}{lr}\text { 1. Introduction } & 1\end{array}$

2. Antenna and Model Design $\quad 1$

$\begin{array}{lr}\text { 3. Results } & 4\end{array}$

4. Discussion and Conclusions $\quad 12$

5. References and Notes $\quad 13$

$\begin{array}{ll}\text { Distribution List } & 14\end{array}$ 


\section{List of Figures}

Fig. 1 Manual image of ETS-Lindgren model 3164-06 horn. Image provided courtesy of ETS-Lindgren. The red plastic structures provide mechanical support to the metal blades.

The Vivaldi-like blade pairs are fed by means of SMA connectors on the base.....................2

Fig. 2 FEKO model of the ETS-Lindgren 3164-06 antenna without base structure ....................3

Fig. 3 Feeds in the FEKO model are the (cylindrical) wires that connect the corresponding blades of each pair. Here the $\mathrm{V}$-port labeled on the antenna corresponds to the horizontal wire and $\mathrm{H}$-port to the vertical wire.

Fig. 4 FEKO model with a simplified base. The square plate base is separated from the blades by $5 \mathrm{~mm}$.

Fig. 5 Gain from the FEKO models and ETS-Lindgren measured gain of a 3164-06 antenna. ETS-Lindgren gain data curve image courtesy of ETS-Lindgren. Directivity data generated from the ETS-Lindgren table. ${ }^{3}$

Fig. 6 ARL-measured and FEKO-modeled S11 compared ................................................6

Fig. 7 FEKO-modeled VSWR and the VSWR inferred from the ARL S11 measurements (top). From the ETS-Lindgren manual, a typical VSWR for the 3164-06 antenna (bottom). Image provided courtesy of ETS-Lindgren.

Fig. 8 A comparison of the modeled E-plane gain patterns and ARL-measured gain patterns.....8

Fig. 9 ETS-Lindgren manual typical 3164-06 gain patterns from a V-port excitation.................9

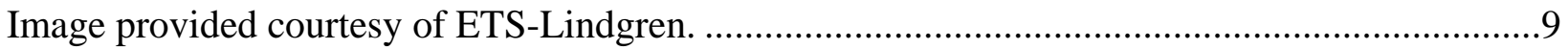

Fig. 10 A comparison of the modeled E-plane gain patterns and ARL-measured gain

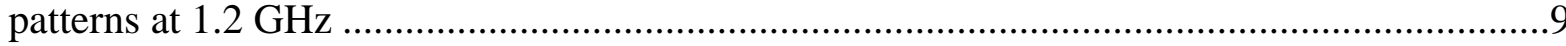

Fig. 11 A comparison of the ARL-modeled and measured antenna beam widths ....................10

Fig. 12 E-plane (red) and H-plane (black) beam widths from ETS-Lindgren manual. Image provided courtesy of ETS-Lindgren.

Fig. 13 FEKO modeled gain and front-to-back ratio compared with a "typical” front-toback ratio as given by the ETS-Lindgren's data ${ }^{3}$. 


\section{Acknowledgments}

I wish to acknowledge Kyle Gallagher and Brian Phelan, both students of Pennsylvania State University working at US Army Research Laboratory (ARL), as well as Gregory Mazzaro, formerly an ARL employee, now at the Citadel in South Carolina, for producing and supplying the “ARL measured” antenna characterizations I used in this report. Also, I wish to acknowledge Marc Ressler for helpful discussions. 
INTENTIONALLY LEFT BLANK. 


\section{Introduction}

For our radar to seek objects on or under the ground, we need an antenna that covers a very wide frequency range, preferably from a few hundred $\mathrm{MHz}$ to several GHz. In particular, we have evaluated the ETS-Lindgren open boundary quad-ridged horn, model 3164-06. This antenna appears to cover our desired range using just 1 antenna, which is clearly an advantage over using multiple antennas. Also, by virtue of its orthogonally placed input feeds, the polarization can be quickly switched electronically, an advantage that improves its ability to see a variety of objects.

In this report, I present results from computer modeling of a 3164-06 antenna and compare these results with measurements to help confirm the characteristics of the antenna. I used FEKO computational electromagnetics software to model the antenna and compute many of its characteristics. Initially, I describe the antenna and its models. Then I cover the predicted and measured gain, S11 parameter, voltage standing wave ratio (VSWR), and 3-dB beam width. Subsequently, I show some of the field or gain patterns. Finally, I follow with some discussion and conclusions.

\section{Antenna and Model Design}

Figure 1 is an image of the ETS-Lindgren 3164-06 horn antenna captured from the data pdf. ${ }^{1}$ It has 2 pairs of blades, both Vivaldi-like antennas, orthogonal to each other, as shown in Fig. 1. The holes in the blades are not modeled, and it is believed that the only purpose is to lighten them. The base houses the feeds, one for each of the pairs. The cross section of the base perpendicular to the horn axis is a square with smoothed corners. The horn is specified on its data sheet ${ }^{1}$ to have a length of $51.4 \mathrm{~cm}$ with both aperture widths at $50 \mathrm{~cm}$. In the antenna's manual $^{2}$ on page 22, its dimensions are described as being 50.8 x 50.8 x $50.8 \mathrm{~cm}$, while a diagram on page 28 shows dimensions of 51.5 (total length) x 50.8 x $50.8 \mathrm{~cm}$. 


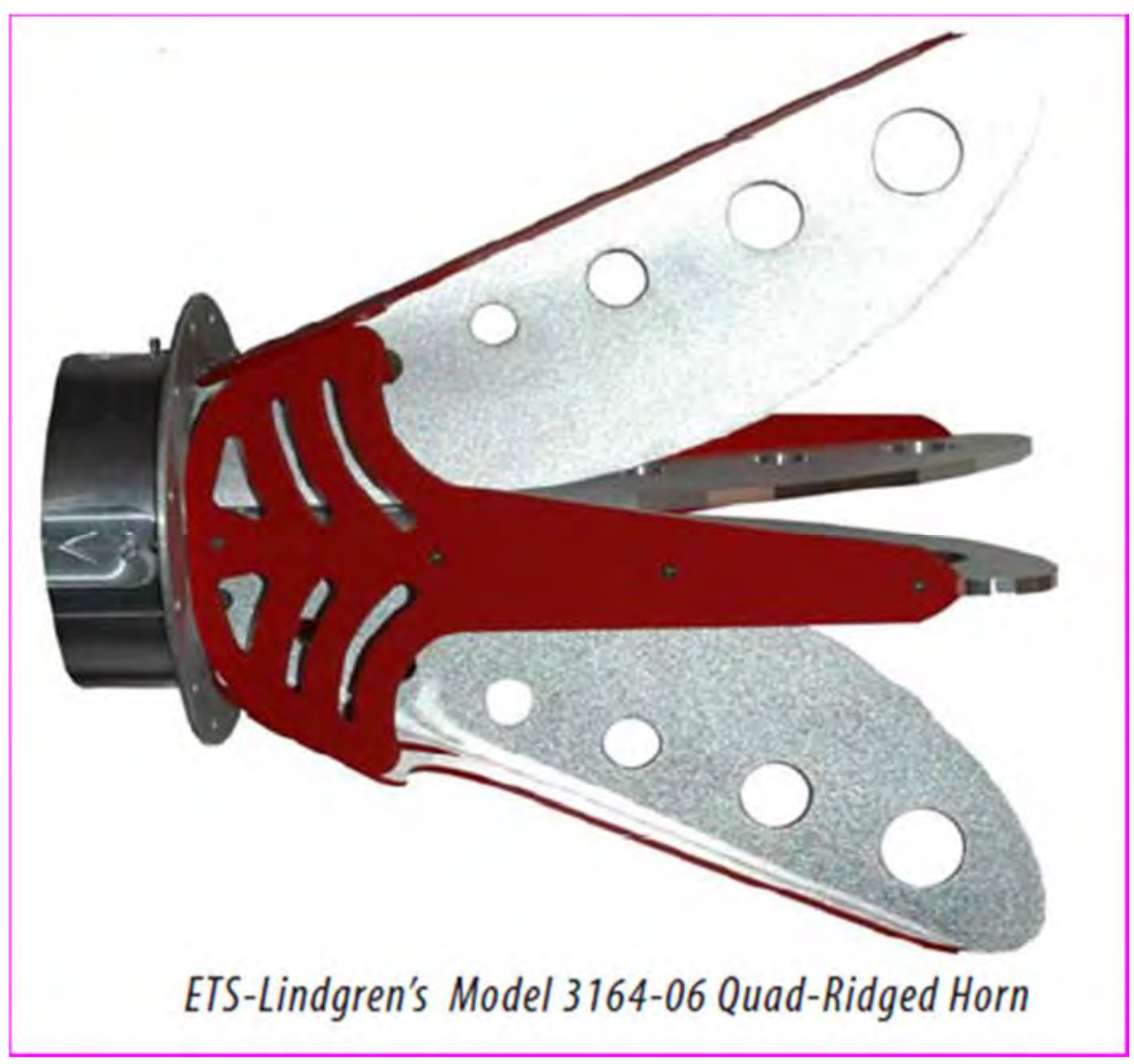

Fig. 1 Manual image of ETS-Lindgren model 3164-06 horn. Image provided courtesy of ETSLindgren. The red plastic structures provide mechanical support to the metal blades. The Vivaldi-like blade pairs are fed by means of SMA connectors on the base.

Figure 2 shows the FEKO model geometry of the antenna without a base structure. The holes in the blades are not modeled as it is believed that their only purpose is to lighten the antenna. Figure 3 zooms in on the feed end of the antenna model. The location of the feeds is similar to those in the antenna and touches both blades, but in the actual antenna one side of each wire passes through that blade in a coax fashion as well as through the adjacent base out to an SMA connector. The excitation in the FEKO feed wires is placed at midpoint on the wires. 


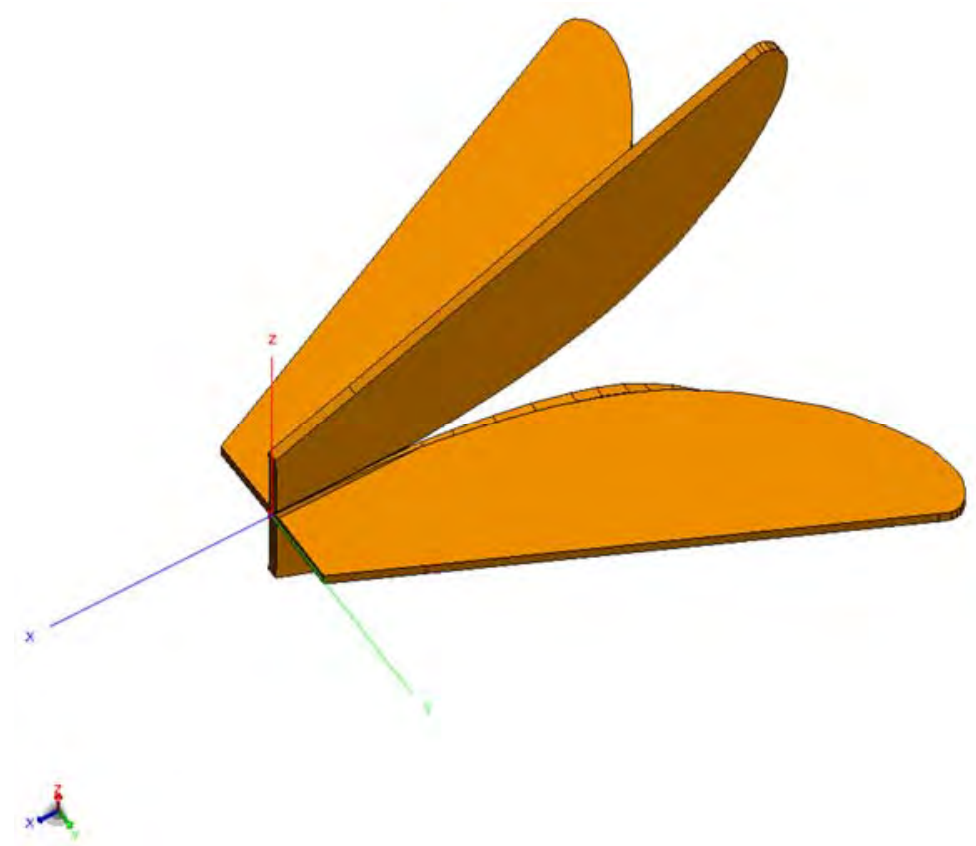

Fig. 2 FEKO model of the ETS-Lindgren 3164-06 antenna without base structure

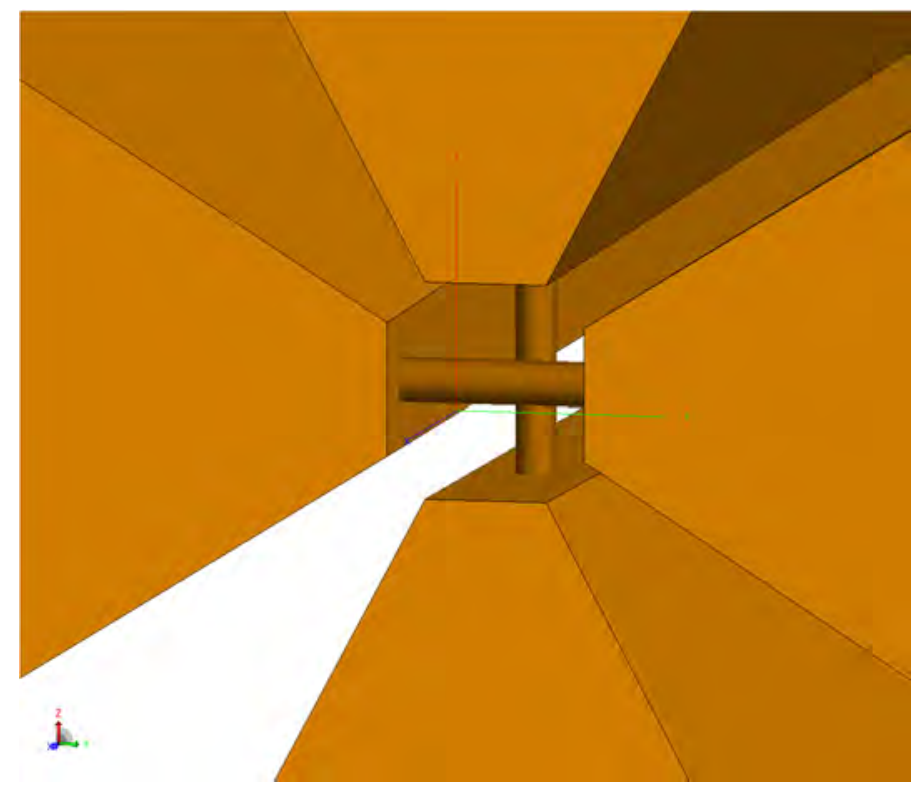

Fig. 3 Feeds in the FEKO model are the (cylindrical) wires that connect the corresponding blades of each pair. Here the V-port labeled on the antenna corresponds to the horizontal wire and H-port to the vertical wire.

Two basic FEKO models were used to compute the characteristics of the antenna, one without a back or feed housing as in Fig. 2 and one with a square plate separated from the base by $5 \mathrm{~mm}$ as in Fig. 4 to try to approximate the shielding effect that the base would actually provide. These 
simplified models were used in the calculations for this report because the memory requirements of the calculations for a more complete base structure could not be met with the available computer.

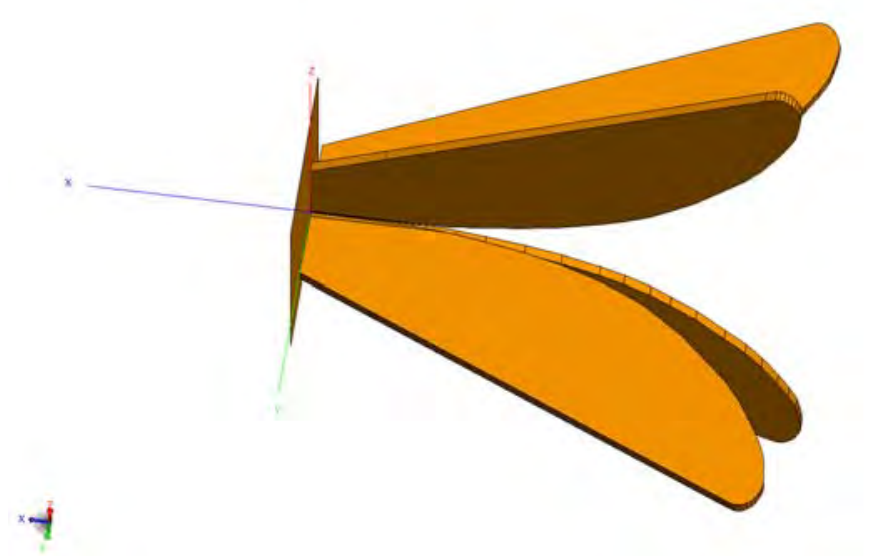

Fig. 4 FEKO model with a simplified base. The square plate base is separated from the blades by $5 \mathrm{~mm}$.

\section{Results}

Figure 5 shows the gain computed with the FEKO models compared with the measured gain over the frequency measured by ETS-Lindgren ${ }^{1}$ from 1 of their antennas. In this case, the FEKO model with the simple back plate compares very favorably with the measured gain. The model without the plate has the same shape, but is 2 or $3 \mathrm{~dB}$ lower. The difference between V-port and $\mathrm{H}$-port gains modeled by FEKO is much less than $1 \mathrm{~dB}$ and is not shown. 


\section{Gain for ETS Lindgren 3164-06 Antenna}

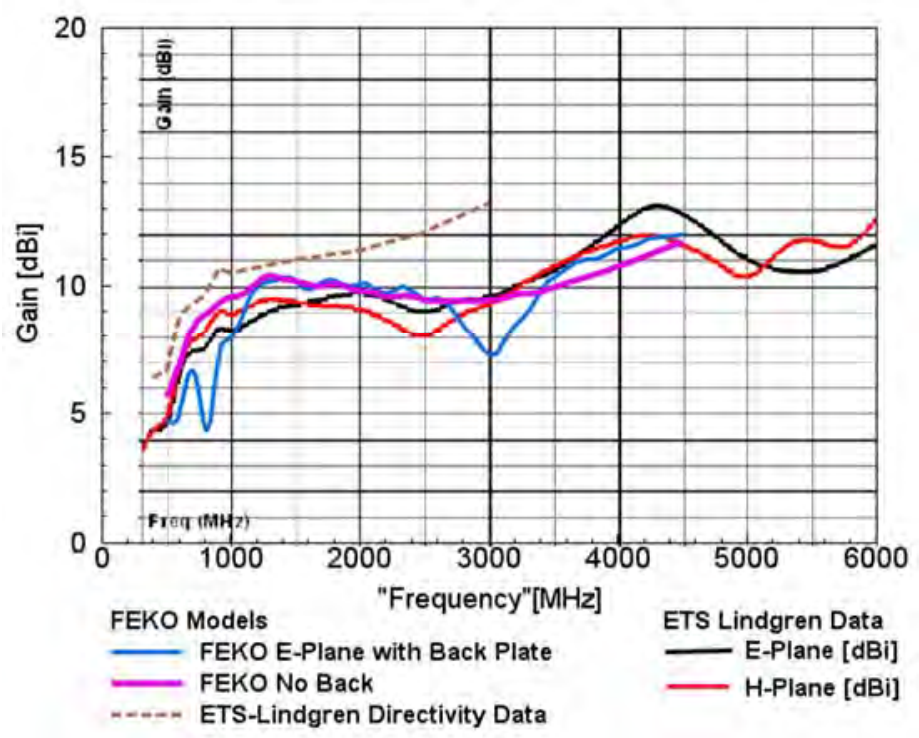

Fig. 5 Gain from the FEKO models and ETS-Lindgren measured gain of a 3164-06 antenna. ETS-Lindgren gain data curve image courtesy of ETS-Lindgren. Directivity data generated from the ETS-Lindgren table. ${ }^{3}$

Figures 6 and 7, respectively, show comparisons of FEKO computed S11 and VSWR with the ARL-measured S11 and its inferred VSWR. In this case, the FEKO model without a back plate gives better agreement with the measurements. In both cases, strong oscillations appear in the results with periods around $300 \mathrm{MHz}$. At low frequencies, the measured periods were about $270 \mathrm{MHz}$, while the FEKO modeled periods were about $330 \mathrm{MHz}$. This difference suggests that the model's effective length was $20 \%$ longer than the actual antenna's effective length, assuming the periods were related to reflections from an effective end of the antenna. The phase shift of these kinds of periods would be attributable to the same kind of difference between the model and antenna's effective lengths. Fig. 7, bottom graph, ${ }^{1}$ shows the ETS-Lindgren's depiction of the typical VSWR for their 3164-06 horn antenna. Although our measurements and calculations show much stronger magnitude oscillations over the frequency spectrum than the ETS-Lindgren characterization shows, the magnitudes are in the same vicinity. The FEKO model with no back plate shows much better agreement with the ARL-measured S11 and VSWR than the model with the back plate. This model also shows better agreement with the ETS-Lindgren VSWR. The difference between the ARL VSWR determination from measurement and the ETS-Lindgren VSWR "typical” characterization does suggest that the ARL measurement should be repeated to confirm whether that difference holds up. 


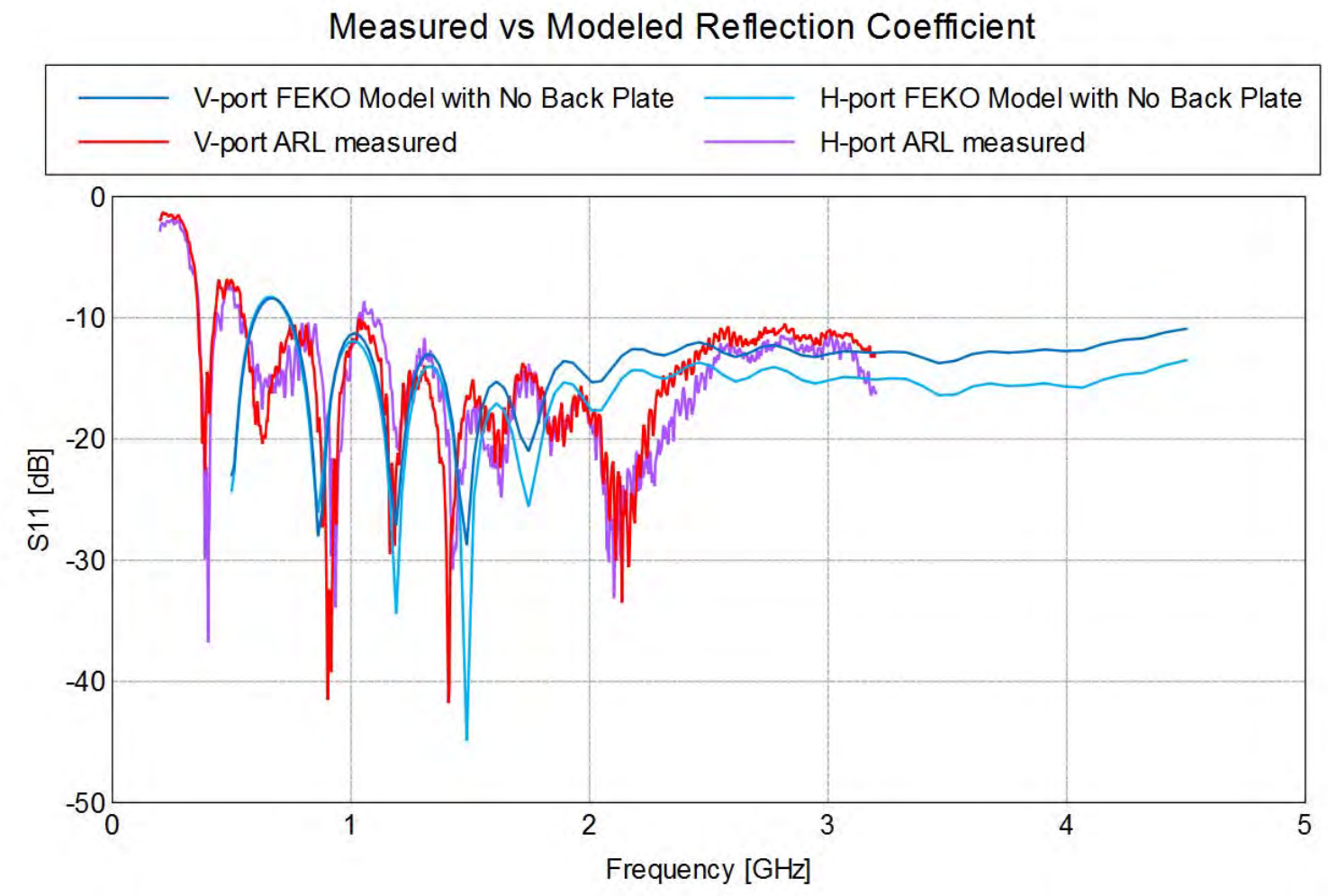

Fig. 6 ARL-measured and FEKO-modeled S11 compared 
Modeled Versus Measured VSWR
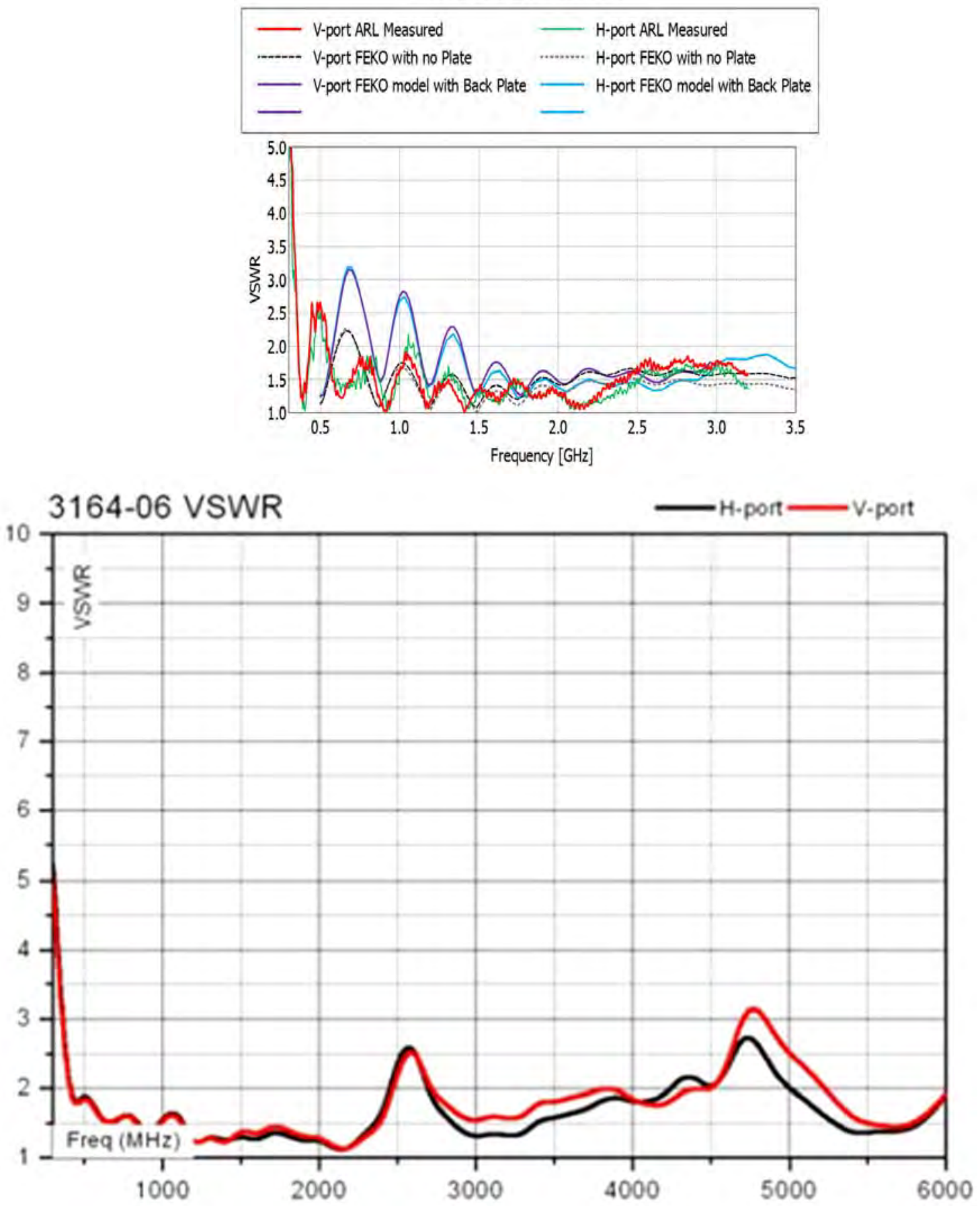

Fig. 7 FEKO-modeled VSWR and the VSWR inferred from the ARL S11 measurements (top). From the ETS-Lindgren manual, a typical VSWR for the 3164-06 antenna (bottom). Image provided courtesy of ETS-Lindgren. 
Figures 8 and 10 show comparisons of the normalized gain or field patterns for the ARLmeasured and modeled patterns at 3 different frequencies, 800, 1000, and $1200 \mathrm{MHz}$. The ARLmeasured and modeled patterns agree with each other, especially at 1000 and $1200 \mathrm{MHz}$. The measured spatial patterns show a higher lobe frequency in agreement with the S11 modulations in the frequency spectrum. Again, this is likely to be from different effective antenna lengths. Another contribution to the rear lobe patterns, especially, is the more complicated rear structures. The front-to-back ratio is higher in the measured antenna, but this may be because of more backward contributions from the poor rear shielding of the FEKO models compared to the actual antenna with the enclosed base shielding the feeds. Figure 9 gives the ETS-Lindgren typical field patterns $^{3}$ for comparison with the E-plane patterns shown in Fig. 8. Their lobes are similar to our measurements and the FEKO model calculation results.
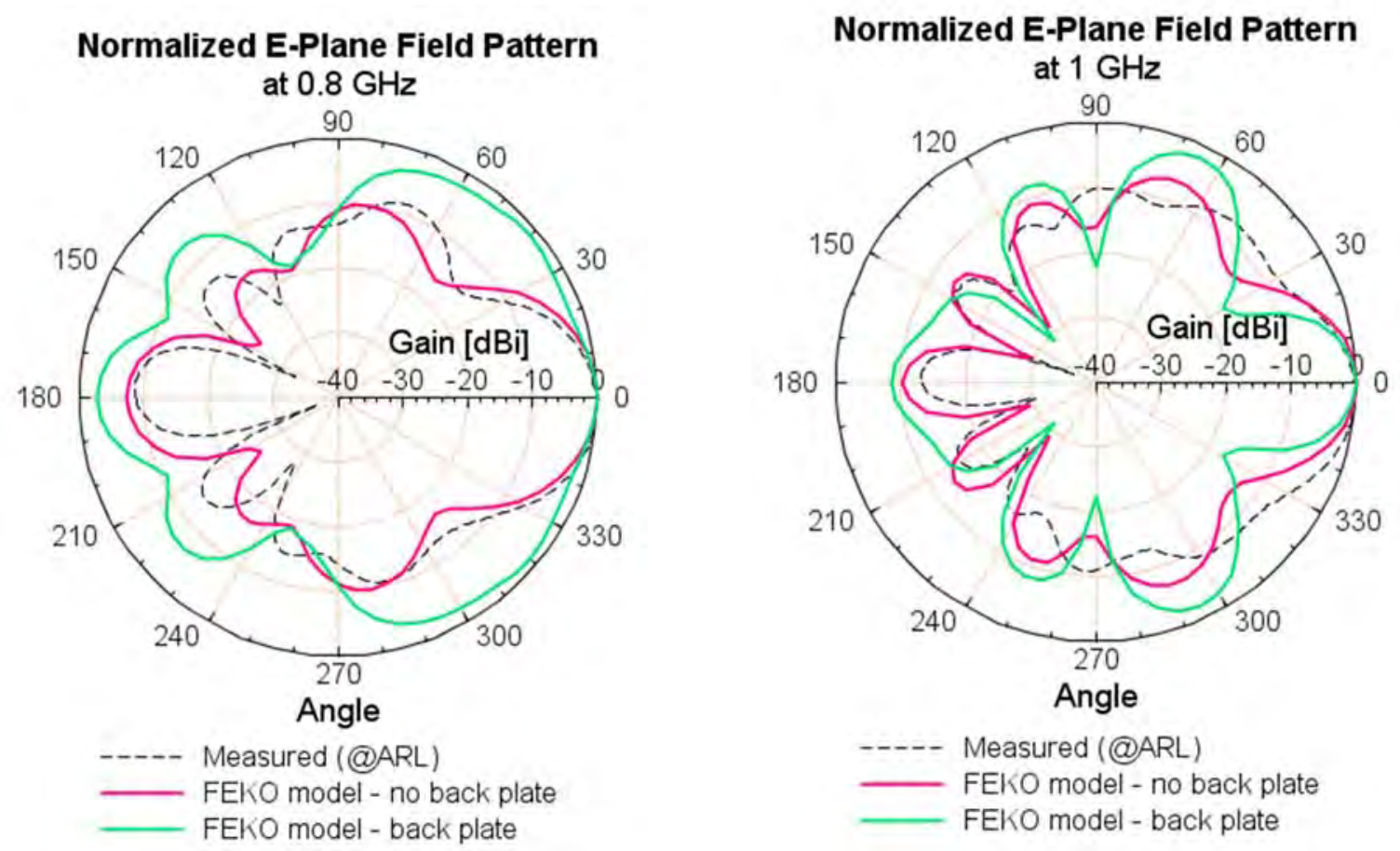

Fig. 8 A comparison of the modeled E-plane gain patterns and ARL-measured gain patterns 


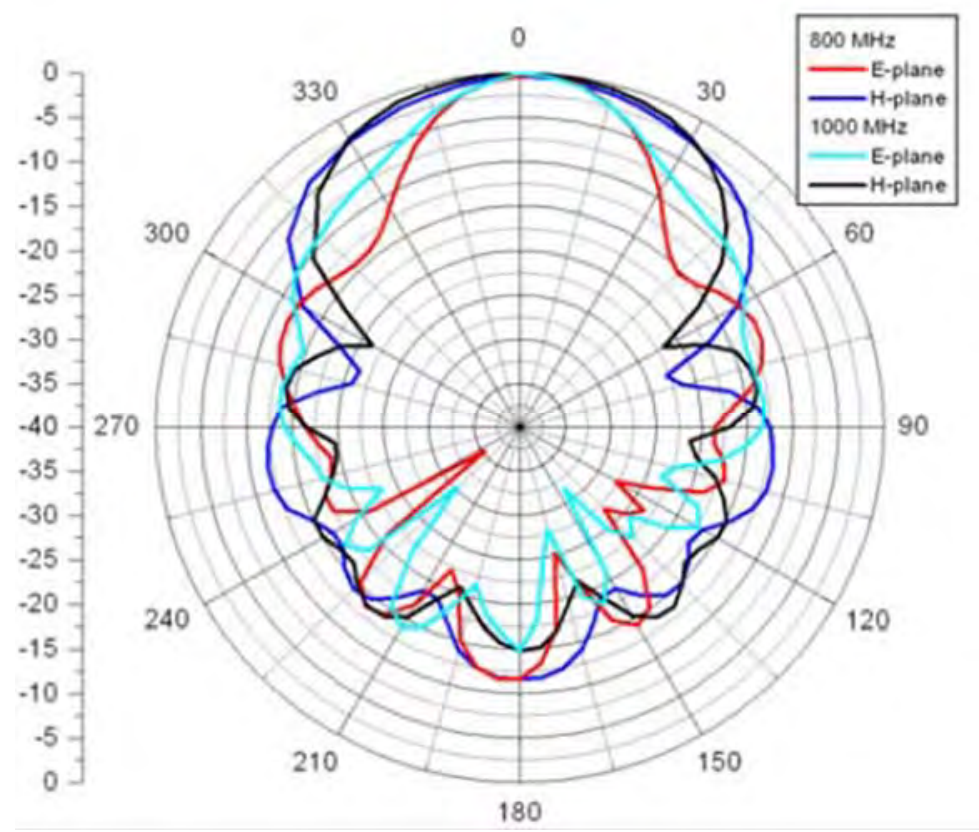

Fig. 9 ETS-Lindgren manual typical 3164-06 gain patterns from a V-port excitation. Image provided courtesy of ETS-Lindgren.

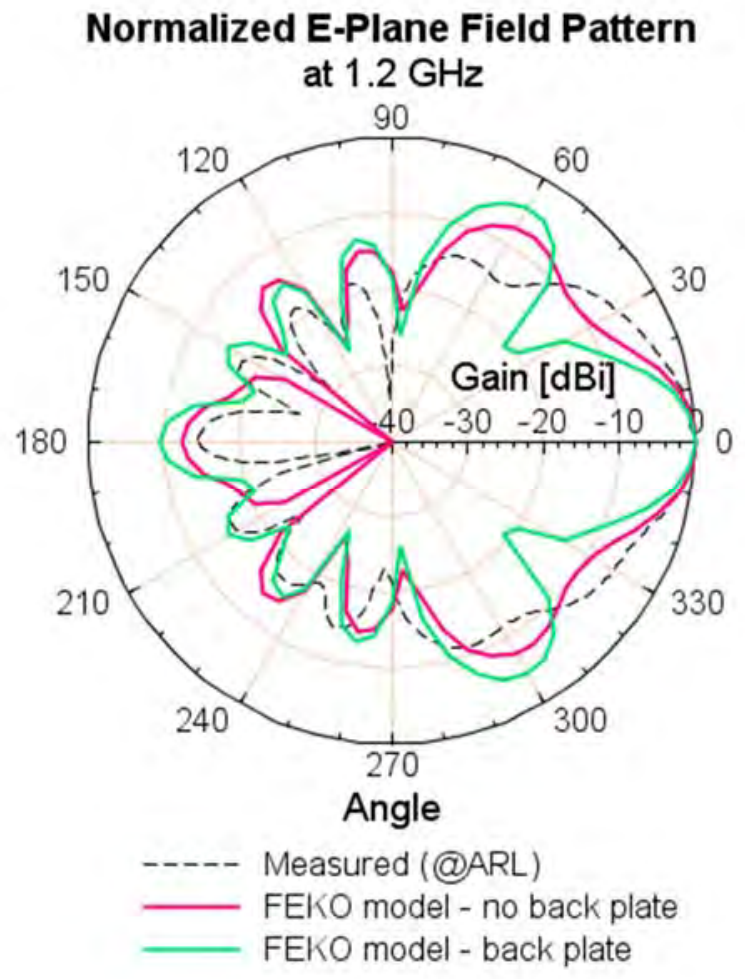

Fig. 10 A comparison of the modeled E-plane gain patterns and ARL-measured gain patterns at $1.2 \mathrm{GHz}$ 
Figure 11 summarizes the modeled and measured beam widths from the computed and measured normalized field patterns from about 300 to $2000 \mathrm{MHz}$. The ARL measurements agree especially well with the FEKO model without a back. As the H-plane gain was far weaker than the E-plane, its value had more uncertainty, at least for the FEKO modeling. Figure 12 shows the ETSLindgren characterization ${ }^{1}$ of the beam width for their 3164-06 antenna. The ARL results agree well with the ETS-Lindgren characterization. The cross-over is at about the same frequency and the wide separation between the E- and $\mathrm{H}$-plane results below $1400 \mathrm{MHz}$ is very similar. Figure 13 compares the front-to-back ratio of the FEKO model with a back plate with the frontto-back ratio for the 3164-06 antenna given by ETS-Lindgren. ${ }^{4}$ The Lindgren data appear to be an average as they do not capture the oscillations in the back gain at $-180^{\circ}$ that would necessarily be present because of the creation of new lobes in the rear as the frequency is increased. Around $800 \mathrm{MHz}$ and above $2 \mathrm{GHz}$, these FEKO model results diverge from the Lindgren data.

Beam Width Referred to $3 \mathrm{~dB}$

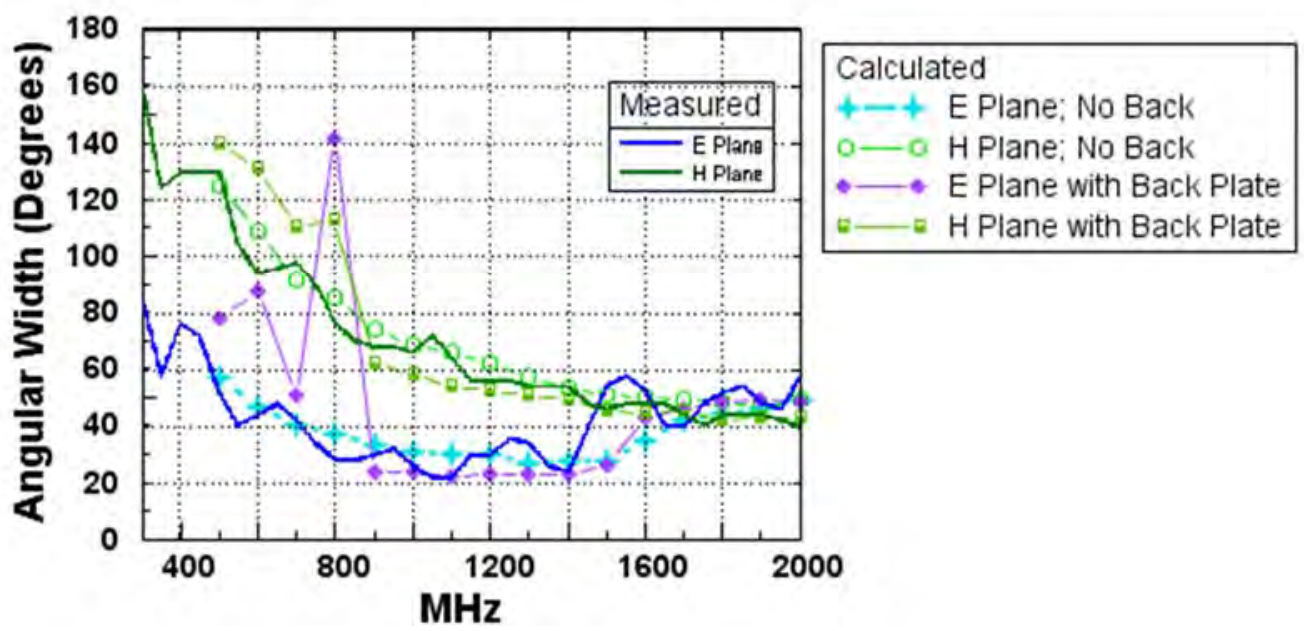

Fig. 11 A comparison of the ARL-modeled and measured antenna beam widths 


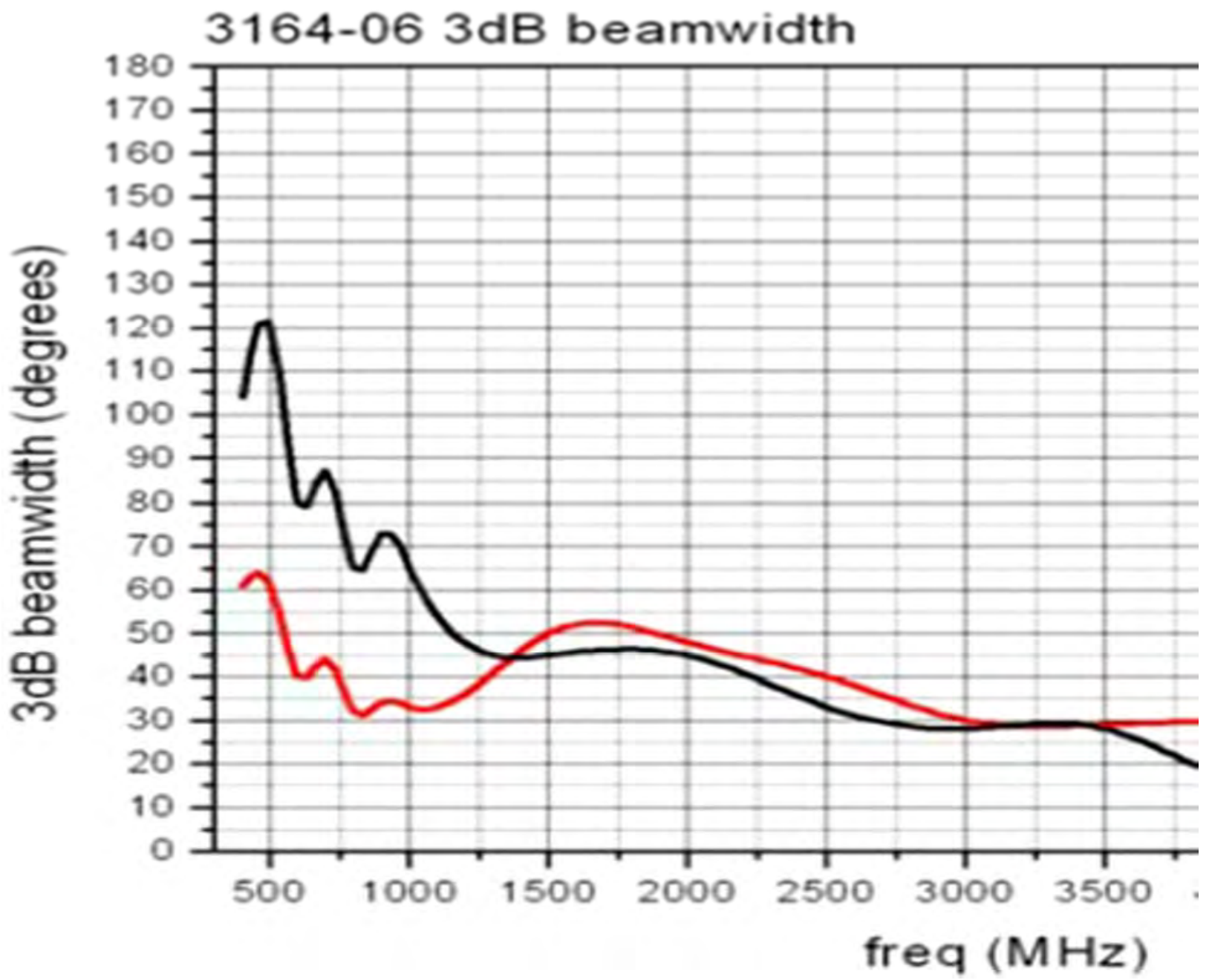

Fig. 12 E-plane (red) and H-plane (black) beam widths from ETS-Lindgren manual. Image provided courtesy of ETS-Lindgren. 
Modeled vs ETS F/B Data

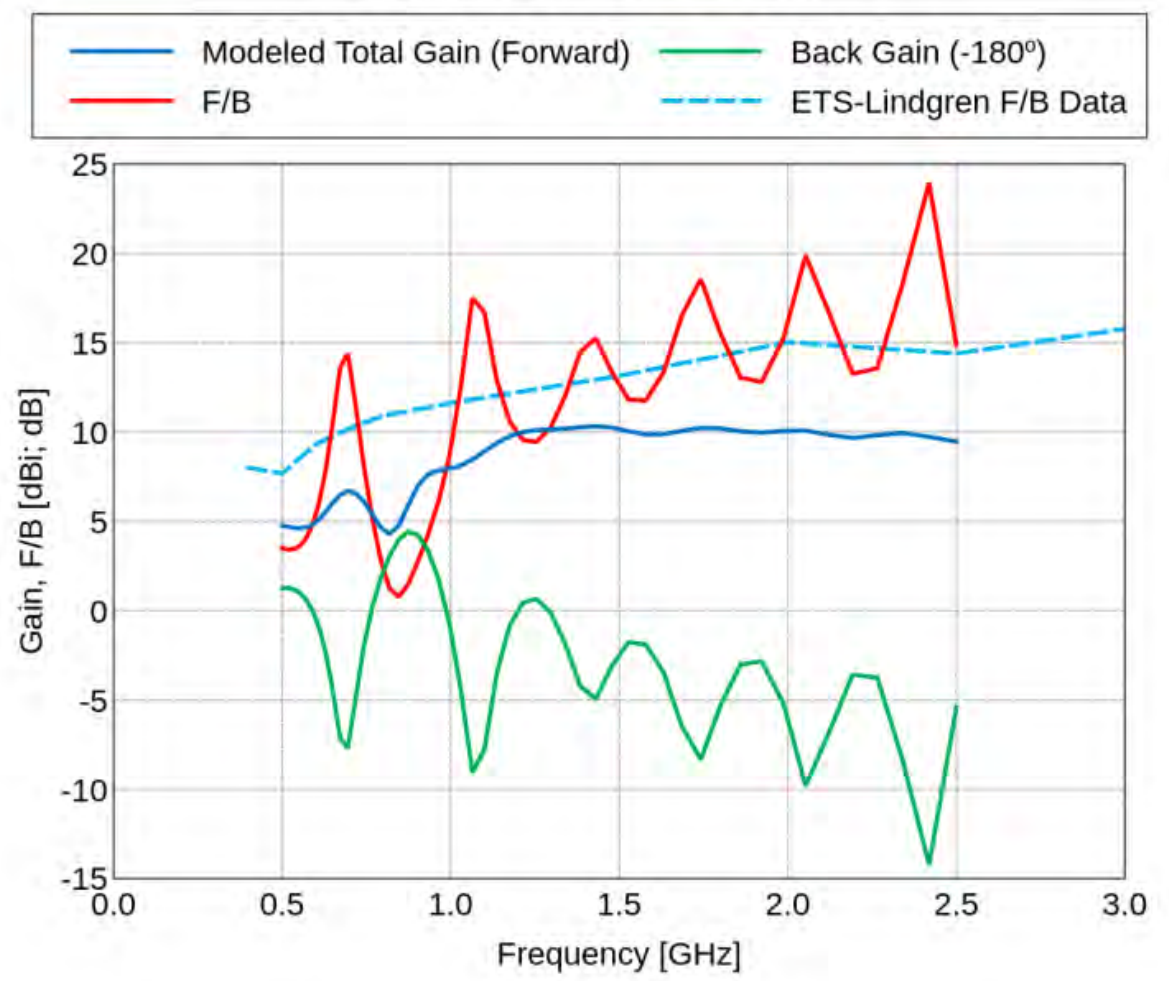

Fig. 13 FEKO modeled gain and front-to-back ratio compared with a "typical" front-to-back ratio as given by the ETS-Lindgren's data ${ }^{3}$

\section{Discussion and Conclusions}

Some discrepancies, especially with the FEKO models, exist partly because of the model simplifications required due to computer memory limitations. In particular, the FEKO models do not have a rear box or feed structure like the 3164-06 actually has. Also, some of the inside and outside model geometry may be slightly in error compared to what the actual horn's shapes and sizes are. The modeled antennas were quite sensitive to the separation between the plates of each pair as small changes in it affected the antenna input impedance. This sensitivity would also affect the FEKO-calculated S11. However, in spite of these limitations, both the ARL model calculations and measurements for the ETS-Lindgren quad-ridged horn model 3164-06 are in reasonable agreement with each other as well as with characterizations given in the ETSLindgren manual. ${ }^{2}$ Strong oscillations in the ARL-measured S11 and VSWR curves suggest a need for repeated measurements of S11 to confirm the behavior of the antenna, and may be an exception to the general agreement in the characterization of the ETS-Lindgren 3164-06 horn antenna (serial number 00146441) that we acquired. 


\section{References and Notes}

1. 3164 data sheet. http://www.ets-lindgren.com/RFAntennas. Viewed August 2014.

2. ETS-Lindgren manual. http://www.ets-lindgren.com/RFAntennas. Viewed August 2014.

3. ETS-Lindgren antenna patterns were measured at the ETS-Lindgren facilities: ETS-Lindgren A2LA certified Calibration Lab with Two anechoic chambers for antenna measurement at the ETS-Lindgren facility in Cedar Park, Texas. See “UsingEMQuestViewerSupplement.pdf” inhttp://www.ets-lindgren.com/AMP-Viewer (accessed 9/2014).

4. http://www.ets-lindgren.com/AntennaPatterns for Model 3164-06 (accessed 9/2014) using EMQuest Viewer in http://www.ets-lindgren.com/AMP-Viewer. 


$\begin{array}{cl}1 & \text { DEFENSE TECH INFO CTR } \\ (\mathrm{PDF}) & \text { ATTN DTIC OCA } \\ 2 & \text { US ARMY RSRCH LAB } \\ (\mathrm{PDF}) & \text { ATTN IMAL HRA MAIL \& RECORDS MGMT } \\ & \text { ATTN RDRL CIO LL TECHL LIB } \\ 1 & \text { GOVT PRNTG OFC } \\ (\mathrm{PDF}) & \text { ATTN A MALHOTRA } \\ 1 & \text { ELEC AND COMPUTER ENGRG DEPT } \\ (\mathrm{PDF}) & \text { THE CITAL, THE MILITARY COLLEGE OF SC } \\ & \text { ATTN G MAZZARO } \\ 9 & \text { US ARMY RSRCH LAB } \\ (\text { PDF }) & \text { ATTN RDRL SER M M CONN } \\ & \text { ATTN RDRL SER M S WEISS } \\ & \text { ATTN RDRL SER M T ANTHONY } \\ & \text { ATTN RDRL SER U B PHELAN } \\ & \text { ATTN RDRL SER U C KENYON } \\ & \text { ATTN RDRL SER U G SMITH } \\ & \text { ATTN RDRL SER U K GALLAGHER } \\ & \text { ATTN RDRL SER U M RESSLER } \\ & \text { ATTN RDRL SER E K TOM }\end{array}$

